\title{
Avaliação nutricional do subproduto da agroindústria de abacaxi como aditivo de silagem de capim-elefante ${ }^{1}$
}

\section{Ana Cristina Holanda Ferreira ${ }^{2}$, José Neuman Miranda Neiva ${ }^{2}$, Norberto Mario Rodriguez ${ }^{3}$, Warley Efrem Campos ${ }^{3}$, Iran Borges ${ }^{3}$}

\author{
${ }^{1}$ Pesquisa financiada pelo CNPq, pela FUNCAP e pela CAPES \\ 2 Universidade Federal do Tocantins \\ 3 Universidade Federal de Minas Gerais.
}

RESUMO - Com o objetivo de avaliar o valor nutritivo de silagens de capim-elefante (CE) contendo o subproduto do processamento de abacaxi desidratado (SAD), utilizaram-se 20 ovinos, machos não-castrados, distribuídos em delineamento inteiramente casualizado, com cinco tratamentos $(0,0 ; 3,5 ; 7,0 ; 10,5$ e $14 \%$ de SAD na silagem) e quatro repetições. Estimaram-se os consumos de matéria seca (MS), proteína bruta (PB), fibra em detergente neutro (FDN), fibra em detergente ácido (FDA) e energia digestível (ED), bem como as digestibilidades de MS, PB, FDN, FDA, hemicelulose e EB e o balanço de nitrogênio (BN). Com a adição de SAD, foram observados aumentos lineares nos consumos de MS, PB, MSD e ED. A adição de $1 \%$ de SAD na ensilagem do capim-elefante resultou em aumento de 16,17 g nos consumos diários de MS e PB. A adição de SAD na ensilagem de capim-elefante promoveu aumento 14,1 g; 0,60 g; e 0,60 Mcal nos consumos diários de matéria seca, proteína bruta e enegia digestíveis, respectivamente. Com a adição de SAD, não houve alterações na digestibilidade de MS (53,3\%), PB (42,1\%) e FDN (55,2\%) das silagens nem no balanço de nitrogênio (2,92 g/dia). Entretanto, o balanço de nitrogênio só atingiu valores positivos quando adicionado SAD à dieta. O subproduto de abacaxi desidratado pode ser adicionado em níveis de até $14 \%$ da matéria natural na ensilagem de capim-elefante, pois melhora o valor nutritivo das silagens e possibilita maiores consumos de matéria seca, proteína bruta, matéria seca e energia digestíveis.

Palavras-chave: ensilagem, gramíneas tropicais, valor nutritivo

\section{Nutritional evaluation of pineapple industry by-product as additive on elephant grass silage}

\begin{abstract}
The present study aimed to determine de nutritional value of mixed elephant grass silages in increasing levels with dehydrated pineapple industry by-product (PAB). Five PAB levels (0.0, 3.5, 7.0, 10.5, and 14.0\%) were tested with 20 male non-castrated sheep in a randomized experimental design of five treatments (PAB levels) and four replications per treatment (sheep). Intake and digestibility of dry matter (DM), crude protein (CP), neutral detergent fiber (NDF), acid detergent fiber (ADF), cellulose (CEL), hemicelulose (HCEL) and energy as well as nitrogen balance were determined. Linear increases on the DM, CP intake and digestible energy occurred as the PAB content increased in the silage. For every increase of $1 \%$ of $\mathrm{PAB}$ in the silage, increments of $16.17 \mathrm{~g}$ and $1.55 \mathrm{~g}$ of DM and CP intakes, respectively, were observed. The addition of PAB in the silage increased the DDM, DCP and DE intake. However, the nutrients digestibility remained unchanged. Mean values were 53.3\%, 42.1\%, 55.2\% and 2.92 g/day for DM, CP, NDF and NB, respectively. NB was positive only with PAB in the rations. It is concluded that additions of PAB in the elephant grass silage up to a level of $14 \%$ in a natural basis increases the digestible nutrients intake.
\end{abstract}

Key Words: ensilage, nutritional value, tropical grass

\section{Introdução}

A estacionalidade na produção de forragem tem sido responsável, entre outros fatores, pela reduzida produtividade dos rebanhos, que, em conjunto com a freqüente variação dos preços dos grãos de cereais e dos suplementos protéicos utilizados na alimentação animal, tem despertado o interesse no aproveitamento de alimentos alternativos.

Nesse contexto, os resíduos agroindustriais podem ser importantes na alimentação de ruminantes, principalmente em situações de baixa disponibilidade de forragem. O resíduo da indústria do processamento de abacaxi tem sido utilizado em algumas pesquisas em substituição a 
alimentos volumosos (Alves et al., 2002; Correia et al., 2002; Lallo et al., 2003) e grãos de cereais (Muller, 1978) e pode ainda ser utilizado como aditivo na produção de silagens de gramíneas tropicais (Oliveira Filho et al., 2002). Rodrigues \& Peixoto (1990a), em pesquisa com ovinos, avaliaram a digestibilidade dos resíduos da indústria do abacaxi e encontraram digestibilidade dos nutrientes superiores a 60\%.

O subproduto da agroindústria do suco do abacaxi é constituído de casca, coroa, brotos da fruta, anexos da fruta, miolo e polpa. A proporção de cada parte da fruta no resíduo da indústria, bem como sua composição química, varia consideravelmente com a variedade da fruta, maturidade, qualidade da produção fotossintética (conteúdo de açúcar) e tecnologia empregada pela fábrica (Muller, 1978).

A adição do subproduto de abacaxi na ensilagem de gramíneas tropicais pode, além de reduzir os custos com alimentação, melhorar as características fermentativas das silagens. Todavia, esta análise deve ser acompanhada da avaliação dos efeitos do subproduto sobre o consumo e a digestibilidade, que podem afetar o desempenho e a saúde dos animais.

Assim, conduziu-se este experimento para avaliar o efeito dos níveis de subproduto do abacaxi desidratado na silagem de capim-elefante sobre o consumo e a digestibilidade dos nutrientes e sobre o balanço de nitrogênio em ovinos.

\section{Material e Métodos}

O experimento foi realizado no Núcleo de Pesquisa em Forragicultura do Departamento de Zootecnia do Centro de Ciências Agrárias da Universidade Federal do Ceará (UFC), em Fortaleza, Ceará. O município de Fortaleza situa-se na Zona Litorânea, a 15,49 m de altitude, 343'02" de Latitude Sul e 38³2'35" de Longitude Oeste.

Estudou-se a adição de cinco níveis $(0,0 ; 3,5 ; 7,0 ; 10,5$ e 14,0\% com base na matéria natural) de adição do subproduto de abacaxi (Ananas comosus L.) desidratado SAD - na ensilagem de capim-elefante (Pennisetum purpureum, Schum). Na confecção das silagens experimentais, utilizou-se capim-elefante proveniente de capineira estabelecida na Fazenda Experimental do Vale do Curu (FEVC), Pentecoste, Ceará, pertencente à Universidade Federal do Ceará (UFC). O capim foi cortado manualmente, aproximadamente aos 70 dias de crescimento, e processado em picadeira de forragem convencional em tamanho de 1 a $2 \mathrm{~cm}$. Posteriormente, foi misturado ao subproduto do abacaxi, originado do processamento da fruta para extração de sucos e polpas.
O subproduto de abacaxi foi desidratado ao sol até que atingisse 13 a 16\% de umidade. Durante a desidratação, o material foi revolvido três vezes ao dia e amontoado à noite, coberto com lona para evitar umidade. Diariamente foram coletadas amostras do material para determinação da umidade em forno microondas, conforme metodologia descrita por Neiva et al. (1998).

O capim-elefante no momento da ensilagem apresentava 20,6\% de MS, 4,3\% de PB, 73,6\% de FDN, 48,8\% de FDA, 24,8\% de hemicelulose, 34,5\% de celulose, 14,3\% de lignina, 23,6 de nitrogênio insolúvel em detergente neutro - NIDN (\% do nitrogênio total), 13,9\% de nitrogênio insolúvel em detergente ácido - NIDA (\% do nitogênio total), 6,8\% de carboidratos solúveis e 4,0 Mcal/kg de MS. O subproduto de abacaxi desidratado apresentava 87,4\% de MS, 9,2\% de PB, 60,7\% de FDN, 24,1\% de FDA, 36,6\% de hemicelulose e 11,3\% de celulose, 10,5\% de lignina, 18,8 de NIDN, 4,1\% de NIDA, 9,2\% de carboidratos solúveis e 4,1 Mcal/kg de MS (Tabela 1).

Como silos experimentais, foram utilizados tambores de plástico com capacidade para $210 \mathrm{~L}$. Após a pesagem e homogeneização do capim-elefante com o subproduto de abacaxi, o material foi colocado nos silos (126 kg de forragem, em densidade de $600 \mathrm{~kg} / \mathrm{m}^{3}$ ) e compactado por pisoteamento por homens. Completado o enchimento, os silos foram fechados com lonas plásticas presas com ligas de borracha. A abertura dos silos foi feita 35 dias após o enchimento.

Para avaliação do consumo e da digestibilidade das silagens e determinação do balanço de nitrogênio, utilizaram-se 20 carneiros não-castrados, sem raça definida, com média de $28 \mathrm{~kg}$ de peso vivo, distribuídos em delineamento inteiramente casualizado com cinco níveis de $\operatorname{SMD}(0,0 ; 3,5$; 7,$0 ; 10,5$ ou $14,0 \%$ ) e quatro repetições, considerando cada animal uma unidade experimental. Para cada animal, foi utilizada silagem de um único silo experimental. Os animais foram pesados no início e no final do experimento, vermifugados e distribuídos por sorteio em cada nível de SAD avaliado. Os animais foram mantidos em gaiolas de metabolismo individuais dotadas de coletores e separadores de fezes e urina, de cochos e bebedouros para fornecimento do alimento, mistura mineral e água à vontade.

O experimento teve duração de 21 dias: 14 dias para adaptação dos animais às dietas e ao ambiente experimental e 7 para avaliação do consumo voluntário, da digestibilidade dos nutrientes e do balanço de nitrogênio.

As silagens foram fornecidas diariamente em dois períodos, manhã (6h30 às 7h30) e tarde (15h30 às 16h30), em quantidade calculada diariamente de acordo com o consumo 
Tabela 1 - Composição química e pH de silagens de capim-elefante contendo subproduto do abacaxi desidratado (SAD)

\begin{tabular}{|c|c|c|c|c|c|}
\hline & \multicolumn{5}{|c|}{ Nível de subproduto de abacaxi desidratado (\%) } \\
\hline & 0 & 3,5 & 7 & 10,5 & 14 \\
\hline Matéria seca (\%) & 19,38 & 20,40 & 23,20 & 24,77 & 27,54 \\
\hline Matéria orgânica (\% MS) & 87,73 & 88,39 & 88,98 & 88,75 & 89,49 \\
\hline Proteína bruta (\% MS) & 4,77 & 5,34 & 5,55 & 5,92 & 5,97 \\
\hline Fibra em detergente netro (\% MS) & 76,55 & 73,44 & 70,99 & 68,99 & 66,41 \\
\hline Fibra em detergente ácido (\% MS) & 48,80 & 45,73 & 42,77 & 42,62 & 39,67 \\
\hline Hemicelulose (\% MS) & 27,74 & 27,71 & 28,22 & 26,37 & 26,75 \\
\hline Celulose (\% MS) & 34,47 & 32,22 & 30,71 & 30,55 & 28,21 \\
\hline Lignina (\% MS) & 14,33 & 13,51 & 12,07 & 12,06 & 11,46 \\
\hline NIDN & 21,64 & 21,35 & 23,41 & 21,11 & 19,94 \\
\hline NIDA & 10,24 & 8,76 & 9,13 & 9,21 & 7,48 \\
\hline Ácido lático (\% MS) & 3,486 & 4,738 & 6,132 & 6,142 & 6,779 \\
\hline Ácido acético (\% MS) & 0,350 & 0,986 & 1,682 & 1,832 & 2,025 \\
\hline Ácido propiônico (\% MS) & 0,024 & 0,075 & 0,026 & 0,041 & 0,078 \\
\hline Ácido butírico (\% MS) & 0,025 & 0,032 & 0,035 & 0,068 & 0,031 \\
\hline $\mathrm{N}-\mathrm{NH}_{3} / \mathrm{NT}$ & 4,30 & 4,67 & 5,75 & 6,32 & 7,50 \\
\hline $\mathrm{pH}$ & 5,89 & 3,84 & 3,65 & 3,80 & 3,83 \\
\hline
\end{tabular}

NIDN - nitrogênio insolúvel em detergente neutro (\% nitrogênio total); NIDA - nitrogênio insolúvel em detergente ácido (\% nitrogênio total); N-NH 3 /NT - nitrogênio amoniacal (\% nitrogênio total).

do dia anterior, para permitir sobra de aproximadamente $15 \%$. Amostras das silagens (100 g) foram retiradas diariamente no momento da pesagem do alimento para cada animal, durante todo o período de coleta de dados, acondicionadas em sacos plásticos, identificadas e armazenadas em congelador a $-10^{\circ} \mathrm{C}$. Ao final do experimento, as amostras referentes a cada animal foram descongeladas e homogeneizadas retirando-se uma amostra de aproximadamente $300 \mathrm{~g}$, que foi processada (pré-seca) para posteriores análises. As sobras foram pesadas pela manhã, antes do fornecimento da nova alimentação, e amostradas (aproximadamente $80 \mathrm{~g}$ ) pelo mesmo procedimento descrito para amostragem dos alimentos oferecidos.

As fezes foram coletadas durante o período de avaliação e pesadas no período da manhã. Do total, retirou-se uma amostra de $10 \%$, que foi acondicionada em freezer a $-10^{\circ} \mathrm{C}$. Ao final do experimento, as amostras referentes a cada animal foram descongeladas e homogeneizadas para retirada de aproximadamente $300 \mathrm{~g}$ do total de cada animal, que foram acondicionados em sacos plásticos, identificados e mantidos em freezer a $-10^{\circ} \mathrm{C}$.

Nas vasilhas coletoras de urina, adicionou-se ácido clorídico 1:1 (20 mL) para evitar perdas de nitrogênio por volatilização. A urina foi medida pela manhã e à tarde, quando foram retiradas alíquotas de $10 \%$ do total, as quais foram acondicionadas em congelador a $-10^{\circ} \mathrm{C}$ até o momento das análises.

Nas amostras das silagens, foram determinados os teores de matéria seca, proteína bruta, fibra em detergente neutro, fibra em detergente ácido, hemicelulose, celulose, lignina, energia bruta, cinzas, NIDN e NIDA. Foram analisados também o pH, o nitrogênio amoniacal, em porcentagem do nitrogênio total $\left(\mathrm{N}-\mathrm{NH}_{3} / \mathrm{NT}\right)$, e os ácidos orgânicos (ácido lático, acético, butírico e propiônico). As análises foram realizadas no Laboratório de Nutrição Animal do Departamento de Zootecnia da Universidade Federal de Minas Gerais, segundo Compêndio Brasileiro de Alimentação Animal(1998).

Com os valores obtidos nas análises da composição química das amostras, foram determinados os consumos de MS e PB, em g/dia e g/UTM (unidade de tamanho metabólico $=\mathrm{PV}^{0,75}$ ), e os consumos de FDN, FDA e hemicelulose, em g/dia e \%PV e consumo de energia digestível (g/dia). Determinaram-se também os coeficientes de digestibilidade do nutrientes e da energia da dieta, bem como o balanço de nitrogênio, conforme metodologia descrita por Silva \& Leão (1979). A partir dos valores de digestibilidade, foram calculados os consumos de MS, PB, FDN e energia digestível.

Para avaliação do efeito dos níveis crescentes de SAD, foram realizadas análise de variância como aproximação do grau de ajustamento dos dados aos modelos linear e quadrático e análise de regressão para avaliar utilizando-se o pacote estatístico Statistical Analysis System (SAS, 1990). A escolha do modelo mais apropriado para cada variável baseou-se na significância dos coeficientes linear e quadrático, utilizando-se o teste t (student) nos níveis 1 e 5\% de probabilidade, e no coeficiente de determinação. Antes dessas análises, verificaram-se as pressuposições de distribuição normal e homocedasticidade dos dados. 


\section{Resultados e Discussão}

Os níveis de adição de SAD na ensilagem do capimelefante não influenciaram $(\mathrm{P}>0,05)$ os coeficientes de digestibilidade dos nutrientes nem os valores de energia digestível da dieta (Tabela 2).

A adição de SAD reduziu os teores de FDN e FDA das silagens, o que pode ser importante para elevar a digestibilidade dos nutrientes nas silagens (Tabela 1). No entanto, mesmo com a redução de 9,13 pontos percentuais nos teores de FDA, a digestibilidade das silagens não foi alterada, portanto, os baixos teores de PB das silagens (Tabela 1), aliados à complexação da proteína com componentes fibrosos (NIDN e NIDA), podem ter afetado significativamente os resultados.

Dietas com baixo teor de PB podem limitar a digestão dos nutrientes por deficiência de compostos nitrogenados para os microrganismos ruminais. Não só a concentração, mas a qualidade da proteína da dieta, pode alterar o mecanismo físico do consumo em ruminantes. Dietas com teor de PB inferior a 7\% ou com baixa disponibilidade de nitrogênio podem reduzir a digestibilidade dos constituintes fibrosos da parede celular e restringir o consumo, como conseqüência da lenta passagem dos alimentos pelo rúmen (Van Soest, 1994). Além disso, os teores de lignina das silagens (Tabela 1), superiores a $10 \%$, também podem ser um componente limitante à digestibilidade, uma vez que seu teor na parede celular está altamente correlacionado à digestibilidade da celulose e hemicelulose (Van Soest, 1994).

Desta forma, a limitação no teor de PB, que não atingiu o mínimo necessário para o bom funcionamento ruminal, aliada ao elevado teor de lignina, pode ter limitado a digestibilidade das silagens, mesmo com a melhoria no nível de alguns nutrientes como FDA e FDN. Contudo, somente as silagens exclusivas de capim-elefante apresentaram digestibilidade da MS inferior a 50\%, índice mínimo para que não haja prejuízo para o desempenho animal (Milford \& Minson, 1966).

Lousada Jr. et al. (2005), avaliando subprodutos da agroindústria do abacaxi, observaram digestibilidade de MS, PB, FDN e FDA de 47,5; 29,0; 50,8 e 51,0\%, respectivamente. Segundo esses autores, as reduzidas digestibilidades dos componentes nutricionais deveram-se ao baixo nível de PB $(8,4 \%)$ e podem ter comprometido a digestão pela deficiência de compostos nitrogenados para os microrganismos ruminais. Assim, os dados obtidos neste estudo são justificáveis, uma vez que os valores de digestibilidade dos nutrientes no SAD foram próximos aos observados na silagem de capim-elefante exclusivo.

Lallo et al. (2002) avaliaram a substituição de 0; 20; 40 e $60 \%$ da silagem de milho pela silagem do resíduo industrial do abacaxi em rações para bovinos em confinamento e observaram decréscimo linear nas digestibilidades de MS e PB. Rodrigues \& Peixoto (1990a,b), avaliando o subproduto do abacaxi in natura e a silagem do subproduto do abacaxi, obtiveram digestibilidade da FDA de 73,61 e 81,32\%, respectivamente, valores superiores aos registrados nas silagens com SAD.

Não houve efeito $(\mathrm{P}>0,05)$ dos níveis de $\mathrm{SAD}$ sobre o balanço de nitrogênio. Contudo, os animais que consumiram as silagens com 7,0; 10,5 e 14\% do SAD apresentaram balanço de nitrogênio positivo, provavelmente em virtude do aumento linear nos consumos de proteína bruta e energia digestível nas silagens com SAD (Tabela 3), que permitiu maior eficiência no aproveitamento do nitrogênio pelas bactérias ruminais (Silva \& Leão, 1979; Van Soest, 1994). Desta forma, as silagens supriram o requerimento de nitrogênio dos animais, fato comprovado pelo ganho de peso médio de 28, 65 e $81 \mathrm{~g} /$ dia obtido com as silagens, ao contrário das silagens de capim-elefante e com 3,5\% do $\mathrm{SAD}$, que apresentaram perda média de 71 e de 26 g/dia de peso vivo, respectivamente.

Tabela 2 - Digestibilidade dos nutrientes, valores de energia digestível e balanço de nitrogênio de silagens de capim-elefante com subproduto de abacaxi

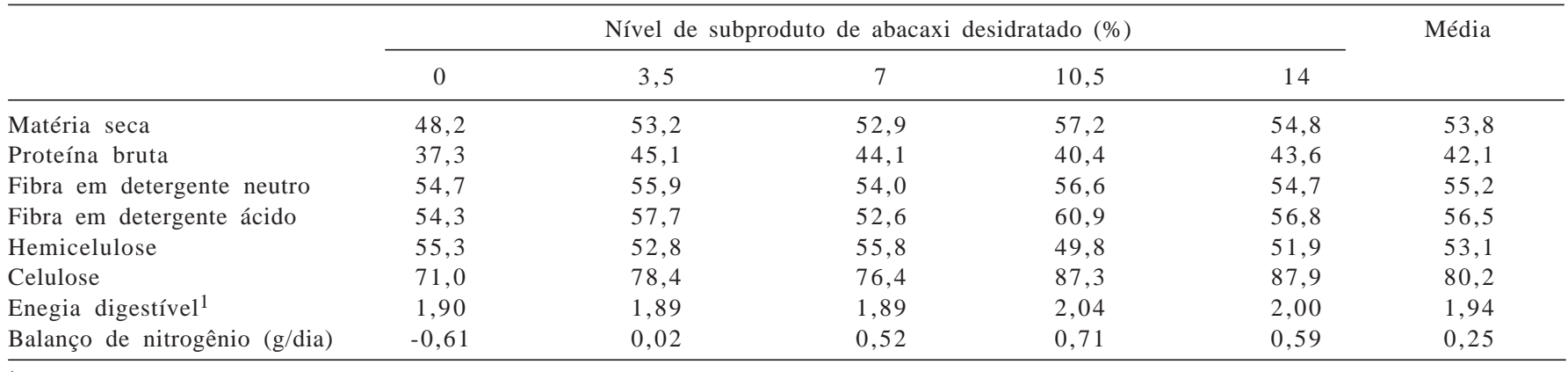

${ }^{1} \mathrm{Mcal} / \mathrm{kg}$ de MS. 
Os resultados obtidos estão de acordo com os observados por Reis et al. (2000), que, trabalhando com níveis crescentes do subproduto do maracujá na ensilagem do capim-elefante (0, 25, 50 e 75\%), obtiveram maior retenção de nitrogênio nos ovinos que receberam as silagens com maior teor de energia, no caso, aquelas contendo esse subproduto. Lousada Jr. et al. (2005) também relacionaram a maior retenção de nitrogênio nos subprodutos de goiaba (4,98 g/dia), maracujá (4,29 g/dia) e melão (5,81 g/dia) aos teores de energia bruta dos subprodutos e, para o SAD, obtiveram retenção de nitrogênio positiva (1,43 g/dia), porém com valores inferiores aos obtidos com os outros subprodutos.

Os consumos de matéria seca (CMS) das silagens aumentaram à medida que foi adicionado o subproduto do abacaxi desidratado (SAD) (Tabela 3). Na análise de regressão, verificou-se efeito linear $(\mathrm{P}<0,01)$ dos níveis de SAD sobre o consumo de matéria seca das silagens, que aumentou $16,17 \mathrm{~g} /$ dia a cada $1 \%$ de SAD acrescido à silagem.

Em experimento com ovinos, Neiva et al. (2006) estudaram o consumo de matéria seca de silagens de capim- elefante contendo subprodutos do processamento do maracujá desidratado (SMD) e observaram que, para cada 1\% de SMD utilizado na ensilagem, o consumo aumentou 19,43g/animal/dia.

O aumento no consumo de matéria seca com a adição do SAD pode estar relacionado ao maior teor de matéria seca das silagens, como observado por Thomas et al. (1961) e Wilkins et al. (1971), que afirmaram que o aumento no consumo de matéria seca está mais relacionado à melhoria no processo fermentativo das silagens com o aumento no teor de MS que ao conteúdo de umidade da silagem. No entanto, sabe-se que o consumo de alimentos possui alguma relação com a umidade da dieta, uma vez que a proporção de volumoso, associada aos maiores conteúdos de água, determina o espaço ocupado no rúmen e pode limitar o consumo pelo efeito da distensão ruminal. Desta forma, a adição do SAD na ensilagem do capim-elefante pode aumentar o consumo por melhorar o processo fermentativo e reduzir o teor de umidade das silagens, pois os dois eventos foram observados neste trabalho.

Tabela 3 - Equações de regressão e coeficiente de determinação $\left(\mathrm{R}^{2}\right)$ para os consumos de nutrientes e energia digestível de silagens de capim-elefante contendo subproduto do abacaxi desidratado

\begin{tabular}{|c|c|c|c|c|c|c|c|}
\hline & \multicolumn{5}{|c|}{ Nível de subproduto de abacaxi desidratado (\%) } & \multirow[t]{2}{*}{ Equação de regressão } & \multirow[t]{2}{*}{$\mathrm{R}^{2}$} \\
\hline & 0 & 3,5 & 7,0 & 10,5 & 14 & & \\
\hline Matéria seca (g/animal/dia) & 388,2 & 421,7 & 535,2 & 500,8 & 631,7 & $\hat{\mathrm{Y}}=382,36+16,17 \mathrm{x}$ & 0,31 \\
\hline Matéria seca (g/UTM) & 34,65 & 41,6 & 48,46 & 47,35 & 59,51 & $\hat{\mathrm{Y}}^{2}=1292,49+140,57 \mathrm{x}$ & 0,49 \\
\hline Proteína bruta (g/animal/dia) & 23,8 & 29,1 & 37,8 & 36,4 & 47,42 & $\hat{\mathrm{Y}}=24,05+1,55 \mathrm{x}$ & 0,47 \\
\hline Proteína bruta (g/UTM) & 2,13 & 2,87 & 3,14 & 3,44 & 4,45 & $\hat{\mathrm{Y}}=2,22+0,149 \mathrm{x}$ & 0,58 \\
\hline $\begin{array}{l}\text { Fibra em detegente neutro } \\
\text { (g/animal/dia) }\end{array}$ & 291,0 & 305,2 & 370,3 & 359,6 & 422,2 & $\hat{\mathrm{Y}}^{2}=91.101+5.643,82 \mathrm{x}$ & 0,21 \\
\hline \multirow[t]{2}{*}{ Fibra em detegente neutro (g/UTM) } & 1,16 & 1,39 & 1,51 & 1,57 & 1,81 & $\hat{\mathrm{Y}}=1,19+0,04 \mathrm{x}$ & 0,31 \\
\hline & & & CFDA & & & & \\
\hline $\begin{array}{l}\text { Fibra em detergente ácido } \\
\text { (g/animal/dia) }\end{array}$ & 181,7 & 187,1 & 216,4 & 219,2 & 246,8 & $\hat{\mathrm{Y}}=210,2$ & ns \\
\hline Fibra em detergente ácido (\%PV) & $0,72 \mathrm{a}$ & 0,85 & 0,88 & 0,95 & 1,06 & $\hat{\mathrm{Y}}=0,74+0,02 \mathrm{x}$ & 0,22 \\
\hline Hemicelulose (g/animal/dia) & 109,3 & 118,1 & 153,8 & 140,1 & 175,4 & $\hat{\mathrm{Y}}^{2}=12846+1146,85 \mathrm{x}$ & 0,34 \\
\hline Hemicelulose (\%PV) & 0,44 & 0,54 & 0,63 & 0,61 & 0,75 & $\hat{\mathrm{Y}}=0,45+0,02 \mathrm{x}$ & 0,41 \\
\hline Celulose (g/animal/dia) & $120,7 \mathrm{a}$ & $122,1 \mathrm{a}$ & $145,8 \mathrm{a}$ & $150,0 \mathrm{a}$ & $164,1 \mathrm{a}$ & $\mathrm{Y}=140,56$ & ns \\
\hline Celulose & $0,48 a$ & $0,56 \mathrm{a}$ & $0,59 a$ & $0,63 a$ & $0,70 \mathrm{a}$ & $\hat{\mathrm{Y}}=0,59$ & ns \\
\hline $\begin{array}{l}\text { Matéria seca digestível } \\
\text { (g/animal/dia) }\end{array}$ & 192,2 & 225,0 & 279,7 & 278,5 & 346,0 & $\hat{\mathrm{Y}}^{2}=39.828+5171,9 \mathrm{x}$ & 0,56 \\
\hline $\begin{array}{l}\text { Proteína bruta digestível } \\
\text { (g/animal/dia) }\end{array}$ & 8,54 & 10,71 & 13,90 & 14,54 & 17,18 & $\hat{\mathrm{Y}}=8,87+0,60 \mathrm{x}$ & 0,42 \\
\hline $\begin{array}{l}\text { Fibra em detergente neutro } \\
\text { digestível (g/animal/dia) }\end{array}$ & 159,4 & 170,5 & 197,7 & 203,3 & 231,2 & $Y=157,9+5,07 x$ & 0,48 \\
\hline Energia digestível (Mcal/dia) & 0,73 & 0,80 & 0,99 & 0,99 & 1,26 & $\hat{\mathrm{Y}}=0,53+0,06 \mathrm{x}$ & 0,48 \\
\hline
\end{tabular}

ns = não-significativo. 
Apesar dos baixos teores de PB (5,5\%) das silagens, que podem restringir o consumo pela redução da disponibilidade de nitrogênio na microflora ruminal, e dos elevados teores de FDN (71,3\%) das silagens, que reduzem o consumo pelo acúmulo de massa fibrosa no rúmen (Van Soest, 1994), o maior nível de SAD (14\%) promoveu aumento de aproximadamente $60 \%$ no consumo de matéria seca em comparação à silagem exclusiva de capim-elefante. Assim, o SAD parece ter melhorado as características nutricionais da silagem de capim-elefante.

Os resultados obtidos neste trabalho foram superiores aos descritos por Okamoto et al. (1988), que avaliaram a ensilagem de resíduo industrial de milho verde e abacaxi para utilização em dietas para ovinos e observaram consumo de matéria seca de 22,0 e 33,8 g/UTM, provavelmente em virtude dos baixos teores de MS (13,97 e 20,41\% de MS, respectivamente).

Lousada Jr. et al. (2005) forneceram para ovinos resíduo do abacaxi desidratado como alimento exclusivo e observaram consumo de matéria seca de 924 g/animal/dia e 64,98 g/UTM, possivelmente porque as silagens tinham maior quantidade de capim-elefante, que se encontrava com baixo valor nutricional (baixo teor de proteína bruta e o alto teor de fibra) (Tabela 1).

Os níveis de $\mathrm{SAD}$ tiveram efeito linear $(\mathrm{P}<0,01)$ sobre o consumo de proteína bruta (CPB), que aumentou 1,55 g/dia, ou 0,149 g/ UTM, a cada 1\% de SAD adicionado à silagem. O efeito linear do SAD sobre o consumo de proteína bruta é reflexo tanto do aumento dos teores de PB como do consumo de matéria seca das silagens contendo o subproduto de abacaxi desidratado.

As silagens com $14 \%$ de SAD proporcionaram aumento de aproximadamente $95 \%$ no consumo de proteína bruta, o que pode justificar a utilização desse subproduto na ensilagem do capim-elefante, uma vez que as características nutricionais das silagens foram melhoradas. Segundo Cunha \& Silva (1977), o fornecimento da silagem de capimelefante como único alimento limita o desempenho dos animais, o que indica a necessidade de suplementos protéicos e/ou energéticos.

Lousada Jr. et al. (2005) forneceram SAD como alimento exclusivo para ovinos e registraram consumo de $\mathrm{PB}$ de 75,27 g/dia e 5,3 g/UTM, o que comprova o maior potencial de fornecimento de PB desse subproduto em comparação ao capim-elefante em estádio de desenvolvimento mais avançado. De modo geral, as silagens com 14\% do SAD possibilitaram consumo de PB satisfatório em comparação aos valores obtidos por Reis et al. (2000) em silagens de capim-elefante com 25\% de resíduos do fruto do maracujá (3,12 g/UTM).
Os consumos de fibra em detergenteneutro ehemicelulose, tanto em \%PV como em g/UTM, apresentaram aumento linear $(\mathrm{P}<0,05)$ de acordo com os níveis de SAD utilizados na ensilagem do capim-elefante.

As maiores ingestões de FDN e FDA se devem ao aumento no consumo de matéria seca das silagens com SAD (Tabela 1). É possível que esse resultado também tenha contribuído para o aumento do consumo de matéria seca das silagens, uma vez que, segundo Mertens (1992), o teor ideal de FDN na dieta não é fixo e varia com o requisito de energia líquida do animal. Assim, quando o volume da dieta é fator limitante, ou seja, a dieta apresenta altos teores de FDN, o animal necessita consumir mais para atender o requerimento de energia.

Lousada Jr. et al. (2005) avaliaram o consumo de FDN de subprodutos de abacaxi, acerola, goiaba, melão e maracujá e ressaltaram que, apesar das semelhanças na origem (subprodutos do processamento de frutos), os subprodutos apresentam grande variação no consumo de FDN, em virtude da natureza da fibra, o que evidencia o conceito preconizado pelo NRC (2001) de que o limite de consumo de 1,4\% PV de FDN em bovinos não pode ser aplicado a esses subprodutos em estudo.

Os valores de ingestão de MS, PB, FDN e energia digestíveis aumentaram de forma linear com a adição de SAD, com aumentos de 11,86 g; 0,6 g; 5,07 g e 0,06 Mcal de energia digestível, respectivamente, a cada $1 \%$ de inclusão de SAD. Esse resultado permite confirmar a afirmativa de que a adição de SAD melhora o valor nutritivo de silagens de capim-elefante.

Os dados observados neste trabalho confirmam os obtidos por Lousada Jr. et al. (2005), que avaliaram o SAD e observaram que é um subproduto superior aos subprodutos de acerola, goiaba e melão. Segundo esses autores, teores relativamente altos de pectina no SAD podem tornar sua utilização interessante, em razão da alta digestibilidade desse nutriente.

\section{Conclusões}

A adição do subproduto de abacaxi desidratado em níveis de até $14 \%$ da matéria natural da forragem melhora o valor nutritivo de silagens de capim-elefante e possibilita maiores consumos de matéria seca, proteína bruta, fibra em detergente neutro e energia digestíveis.

\section{Literatura Citada}

ALVES, G.R.; FONTES, C.A.A; RIBEIRO, E.G. et al. Influência do nível de matéria seca, e de uréia sobre a qualidade de silagens 
contendo polpa de abacaxi, em misturas com bagaço de cana ou feno de Coast cross. In: REUNIÃO ANUAL DA SOCIEDADE BRASILEIRA DE ZOOTECNIA, 39., 2002, Recife. Anais... Recife: Sociedade Brasileira de Zootecnia, [2002]. (CD-ROM).

CORREIA, M.X.C.; COSTA, R.G.; SILVA, J.H.V. et al. Desempenho de caprinos alimentados com níveis crescentes de resíduo agroindustrial de abacaxi em substituição ao feno de capim coast cross. In: REUNIÃO ANUAL DA SOCIEDADE BRASILEIRA DE ZOOTECNIA, 39., 2002, Recife. Anais... Recife: Sociedade Brasileira de Zootecnia, [2002]. (CD-ROM).

COMPÊNDIO Brasileiro de Alimentação Animal. São Paulo: SIDIRAÇÕES rações, 1998.

CUNHA, F.G.; SILVA, D.J. Silagem de capim elefante napier como único volumoso, sem suplementação de concentrado, para vacas de corte no período da seca. Científica, v.5, n.1, p.65-69, 1977.

LALLO, F.H.; PRADO, I.N.; NASCIMENTO, W.G. et al. Níveis de substituição da silagem de milho pela silagem de subproduto industrial de abacaxi sobre a degradabilidade ruminal em bovinos confinados. Revista Brasileira de Zootecnia, v.32, n.3, p.719-726, 2003.

LALLO, F.H.; PRADO, I.N.; ZEOULA, L.M. et al. Níveis de substituição da silagem de milho pela silagem de subproduto industrial de abacaxi sobre a digestibilidade aparente de rações em bovinos confinados. In: REUNIÃO ANUAL DA SOCIEDADE BRASILEIRA DE ZOOTECNIA, 39., 2002, Recife. Anais... Recife: Sociedade Brasileira de Zootecnia, [2002]. (CD-ROM).

LOUSADA JR., J.E.; NEIVA, J.N.M.; PIMENTEL, J.C.M. et al. Consumo e digestibilidade aparente de subprodutos do processamento de frutas em ovinos. Revista Brasileira de Zootecnia, v.34, n.2, p.591-601, 2005.

MERTENS, D.R. Análise da fibra e sua utilização na avaliação de alimentos e formulação de rações. In: SIMPÓSIO INTERNATIONAL DE RUMinAnTES, 29., 1992, Lavras. Anais... Lavras: Sociedade Brasileira de Zootecnia, 1992. p.188-219.

MILFORD, R.; MINSON, D.J. Intake of tropical pasture species. In: CONGRESSO INTERNATIONAL DE PASTAGENS, 9. 1965, São Paulo. Anais... São Paulo: Departamento de Produção Animal da Secretaria de Agricultura, 1966. p.815-822.

MULLER, Z.O. Feeding potential of pineapple waste for cattle. World Animal Review, v.25, n.1, p.25-29, 1978.

NEIVA, J.N.M.; GARCIA, R.; VALADARES FILHO, S.C. et al. Desempenho de bovinos de corte alimentados com dietas à base de silagens e rolão de milho amonizados. Revista Brasileira de Zootecnia, v.27, n.3, p.466-473, 1998.

NEIVA, J.N.M.; NUNES, F.C.S.; CÂNDIDO, M.J.D. et al. Valor nutritivo de silagens de capim-elefante enriquecidas com subproduto do processamento do maracujá Revista Brasileira de Zootecnia, v.35, n.4, p.1843-1849, 2006, 2006 (supl.).

NATIONAL RESEARCH COUNCIL - NRC. Nutrient requirements of dairy cattle. 7.ed. Washington, D.C.: National Academy of Science, 2001. 381p.

OKAMOTO, J.H.H.; ANDRADE, P.; ANDRADE, A.T. Valor nutritivo de silagens feitas com resíduo industrial do milho verde e abacaxi para ovino. Revista Brasileira de Zootecnia, v.17, n.2, p.147-152, 1988.

OLIVEIRA FILHO, G.S.; NEIVA, J.N.M.; PIMENTEL, J.C.M. et al. Avaliação do valor nutritivo de silagens de capim elefante (Pennisetum purpureum) com diferentes níveis de subproduto de pseudofruto do abacaxi (Ananas comosus). In: REUNIÃO ANUAL DA SOCIEDADE BRASILEIRA DE ZOOTECNIA, 39., 2002, Recife. Anais... Recife: Sociedade Brasileira de Zootecnia, [2002]. (CD-ROM).

REIS, J.; PAIVA, P.C.A; Von TIESENHAUSEN, L.M.E.V. et al. Composição química, consumo voluntário e digestibilidade de silagens de resíduo do fruto de maracujá (Passiflora edulis) e de capim elefante (Pennisetum purpureum Schum) cv. cameroon e suas combinações. Ciência e Agrotecnologia, v.24, n.1, p.213-224, 2000.

RODRIGUES, R.C.; PEIXOTO, R.R. Composição bromatológica, digestibilidade e balanço de nitrogênio de resíduos da indústria de abacaxi ensilado. In: REUNIÃO ANUAL DA SOCIEDADE BRASILEIRA DE ZOOTECNIA, 27., 1990, Campinas. Anais... Campinas: Sociedade Brasileira de Zootecnia, 1990a. p.92.

RODRIGUES, R.C.; PEIXOTO, R.R. Avaliação de alimentos. Composição bromatológica, digestibilidade e balanço de nitrogênio de resíduos da indústria de abacaxi ensilado. In: REUNIÃO ANUAL DA SOCIEDADE BRASILEIRA DE ZOOTECNIA, 27., 1990, Campinas. Anais... Campinas: Sociedade Brasileira de Zootecnia, 1990b. p.93.

SILVA, J.F.C.; LEÃO, M.I. Fundamentos de nutrição dos ruminantes. Piracicaba: Livroceres, 1979. 380p.

STATISTICAL ANALYSIS SYSTEM - SAS. Introductory guide for personal computer's. version 7. Cary: 1990. 956p.

THOMAS, J.K.; MOORE, L.A.; OKAMOTO, M. et al. A study of factors affecting rate of intake of heifers fed silage. Journal of Dairy Science, v.44, p.1471-1483, 1961.

Van SOEST, P.J. Nutricional ecology of the ruminant. 2.ed. Cornell University Press, 1994. 476p.

WILKINS, R.J.; HUTCHINSON, K.J.; WILSON, R.F. et al. The voluntary intake of silage by sheep. I. Interrelationships between silage composition and intake. Journal of Agriculture Science, v.77, p.531-537, 1971. 